\title{
Initial material for breeding drought-resistant varieties of spring barley in the conditions of the Volga-Vyatka region
}

\author{
I. Yu. Zaytseva*, L.V. Mamaeva, I. N. Shchennikova, L. P. Kokina, and E. V. Dyagileva \\ Federal Agricultural Research Center of the North-East named N.V. Rudnitsky, 610007 Kirov, \\ Russian Federation
}

\begin{abstract}
Water scarcity has a significant impact on plants, quality and quantity of crops. On the soils of the northeast of European Russia, instability of precipitation is one of the main factors negatively affecting barley productivity. To assess the drought tolerance level, we used the RSR (root-to-shoot ratio) indicator, which shows the relative redistribution of fluxes of plastic substances between root and aerial organs. Evaluation of 57 collection accessions of spring barley of various ecological and geographical origins was carried out. As a result of the research, sources of breeding of valuable traits were identified for further breeding work on the creation of barley varieties adaptive to the conditions of the Volga-Vyatka region. The accessions Bonita, Bionic, Cooper, Danuta, 752A, NCL 95098, local sample from India (k-3506), Odessky 115, Rodos, Kazminsky, Polarny 14, Adam, Bear, Medicum 11, Irbe (PR-3528), Mie, 121-13, and C-105 are characterized by resistance to osmotic stress at the early stages of organogenesis. For further breeding work drought-resistant varieties NCL 95098, Cooper, Bonita, Danuta, Mie, Rodos, Kazminsky, Adam, Bear, Medicum 11, Irbe (PR-3528), 752A, Polarny 14, and C-105, distinguished by the elements of plant productivity, are advisable to use taking into account their positive qualities. The rest of the drought-resistant accessions are recommended to be included in crosses with varieties having higher productivity.
\end{abstract}

\section{Introduction}

Water shortage is a problem facing modern agriculture. Water shortage has a great impact on plants, on the quality and quantity of yield. Drought and desertification cause an annual global loss of $\$ 42$ billion in agriculture. Droughts are increasingly repeated in vast agricultural areas and are causing great damage to agriculture [1,2].

The Volga-Vyatka region is considered a zone of sufficient humidification; however, one of the main factors negatively affecting barley yields is the instability of precipitation with a 3-5-fold deviation from the average annual norm, as well as an increase in average monthly temperatures during growing season, which significantly increase the stress pressure on plants $[3,4,5]$. Droughts, which have increased in recent years, coincide with

\footnotetext{
${ }^{*}$ Corresponding author: irina-zajjceva30@rambler.ru
} 
critical phases in plant development, especially during seedlings. Due to the weak development of the root system, barley does not tolerate spring drought $[6,7]$. The suppression of the root system due to drought is one of the main reasons for the decrease in yield, as plants lose the ability to provide themselves with moisture and necessary minerals, the sensitivity of leaves is increased, normal conditions of photosynthesis and carbon nutrition are violated, the period of grain filling and the grain mass is restricted, etc. [8,9]. Breeding of cultivars with rapidly developing root system is important [10]. In drought conditions, seminal roots play a major role, which determine the initiation and growth of nodal roots [4].

When studying the gene pool of the initial material, it is important to choose the correct selection criteria, taking into account the conditions of the environment, which largely determines the solution to the problem of stabilizing grain production in the regions. This approach allows to judge the hereditary features of germination with a lack of water, to control the ability of plants to resist the lack of moisture in the early stages of development which are most sensitive to stresses. Differences between cultivars in the seedlings phase have been found to persist as a genetic trait in adult plants $[4,11,12]$.

In order to accelerate the breeding assessment of the drought resistance of cultivars, laboratory methods are increasingly used of diagnosing the state of seeds and seedlings by growing them in solutions of osmotic that simulate moisture deficiency, since they make it possible to conduct studies during the whole year and analyze a large number of accessions [13].

During growth process, plants are often exposed to changing stress situations, as a result of which its' adaptive capabilities are expanded [14]. The creation and manufacturing application of drought-resistant cultivars with high adaptability, suitable to local conditions, capable of realizing natural and technological resources with high returns, is one of the most important tasks of breeding. In solving this problem, the leading role belongs to the scientifically based selection of the initial material.

\section{Materials and methods}

The research was carried out in 2018-2020 in the Federal Agricultural Research Center of the North-East (FARC, Kirov, Russian Federation). Fifty seven collection accessions of spring barley of various ecological and geographical origins obtained from the world collection of All-Russian Institute of Plant Genetics Resources named after N.I. Vavilov were evaluated.

The collection was studied in accordance with the International Classifier [15] and methodological guidelines [16].

The cv. Belgorodsky 100 recommended by a local branch of the State Commission for the Testing and Protection of Breeding Achievements in the Kirov Region, was adopted as a standard.

Drought resistance of spring barley was studied according to the method [17]. To this end, 30 barley seeds were laid out on filter paper in pre-washed and sterilized Petri dishes in 3-fold repetition for the control and test. Distilled water was used as the control, and 7\% solution of PEG-600 was used in the test. Seed germination was carried out in thermostats at a constant temperature of $22{ }^{\circ} \mathrm{C}$. In each variant, germination energy (on the third and fifth days) and germination capacity (on the seventh day) were determined.

The percentage of germinated seeds $(\mathrm{P})$ was determined by formula $(1)$ :

$$
\mathrm{P}=\mathrm{a} / \mathrm{b} * 100 \%,
$$

where a - the average number of seeds germinated in PEG-600 solution (pcs.);

$\mathrm{b}$ - average number of seeds germinated in control solution (pcs.). 
The higher the percentage of seed germination in the PEG-600 solution, the more drought-resistant is the accession.

At the end of the test, the number of roots, the dry root mass and dry shoot mass, the RSR (root-to-shoot ratio) and the relative RSR were determined.

The RSR in the control and test variants was determined by formula (2):

$$
\mathrm{RSR}=\frac{\text { root dry mass }}{\text { shoot dry mass }} * 100 \%
$$

The relative RSR was determined by formula (3):

$$
\text { Relative } \mathrm{RSR}=\frac{\mathrm{RSR} \text { in test solution }}{\mathrm{RSR} \text { in control solution }} * 100 \%
$$

Statistical processing of data was performed by ANOVA according to the procedure [18]. The significance of the differences between test and control variants was established by Student's t-criteria.

Mathematical analysis of the material was carried out using the Microsoft Office Excel computer program and the breeding-and-genetic computer program "AGROS 2.07."

\section{Results and discussion}

There has long been known a positive correlation between the ability of seeds to germinate in osmotic solutions and its drought resistance. On the one hand, this ability reflects the hereditary property of germinating with relatively low water content; on the other hand, the existence of a high suction power that ensures the rapid absorption of the desired amount of water. The high suction power of seeds causes not only a better germination with a lack of moisture, but also the formation of a more powerful primary root system which is important for the further vital activity of plants especially in drought, i.e. the properties of the seedling have a greater effect on the formation of drought resistance in an adult plant [17].

The germination energy of collectible accessions on the third day in the control varied from $16.7 \%$ (cv. Medicum 176) to $95.7 \%$ (cv. Odessky 115), in the test variant - from $10.0 \%$ (cv. Medicum 176) to $92.2 \%$ (cv. Kufal') and on average in cultivars amounted to $68.7 \%$ (control) and $45.3 \%$ (test variant). On the fifth day, the number of germinated seeds ranged from $25.6 \%$ (cv. Medicum 176) to $96.7 \%$ (cv. Odessky 115), in the test - from $25.6 \%$ (cv. Medicum 176) to $93.3 \%$ (cv. Kufal'); on average $77.0 \%$ and $62.8 \%$, respectively. Laboratory germination capacity (on $7^{\text {th }}$ day) varied from $36.7 \%$ (cv. Medicum 176) to $97.8 \%$ (cv. Odessky 115) in control variants and from $28.9 \%$ (cv. Medicum 176) to $93.3 \%$ (cv. Kufal') in test variant and averaged $79.3 \%$ and $65.7 \%$, respectively (Fig. 1). 


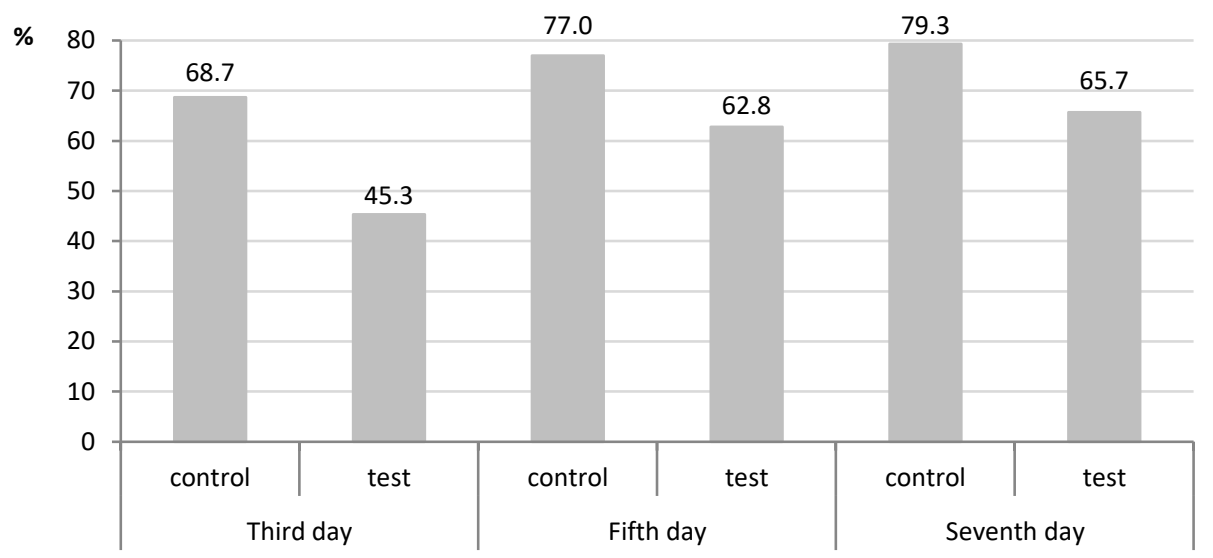

Fig. 1. Germination of seeds of collection accessions under osmotic stress

According to drought resistance (percentage of germinated seeds), the studied cultivars were divided into the following groups:

- highly resistant (percentage of germinated seeds - 81-100\%): Novichok, Bionic, Kazminsky, Shchedry, Naran, 999-93, Forward, 121-13, Omsky golozerny, Olenok (Russia), Syabra Adam, Raider, Kufal', Lipen' (Republic of Belarus), Cooper (Estonia), Sultan (the Netherlands), Orthega, Danuta, Calcule (Germany), 752A (Switzerland), Bonita, NCL 95098 (Argentina), Landrace (Peru), Local cultivar from Afghanistan (k5983), Local cultivar from India (k-3506), Local cultivar from China (k-2929), Makbo (Australia), Odessky 115 (Ukraine), Rodos (Poland), Bear (USA), CDC MC Gwire (Canada), Evergreen (Denmark), 2033E (France), Medicum 11 (Kazakhstan), Irbe (PR3528) (Latvia);

- with a resistance above average (percentage of germinated seeds - 61-80\%): Belgorodsky 100, Bios-1, Polarny 14, C-105 (Russia), Crusades (UK), Filippa (Sweden), Haxby (USA), Local cultivar from China (k-2930), Mie (Estnoia), Isssota (Germany), Yukatan (Ukraine), Medicum 125, Medicum 176 (Kazakhstan);

- medium-resistant (percentage of germinated seeds - 41-60\%): Mentor (Denmark), Mauritia (Germany), Respect (Czech Republic), Fitzroy (Australia), Badyory (Ukraine), Dokuchaevsky 10, Buyan, Forsazh (Russia).

Cv. Bionic, Naran, CDC Mc Gwire, Medicum 11, Omsky golozerny and Kufal' were highly resistant to osmotic stress. The percentage of germinated seeds in these cultivars was higher than that of other cultivars and equaled $100 \%$. Also, a high percentage of germinated seeds were characterized by cultivars 752A (98.5\%), Novichok (97.6\%), Irbe (PR-3528) (97.4\%), Bonita (96.1\%), Calcule (95.6\%), Raider (94.9\%), Danuta (94.2\%), Sultan (93.3\%), local cultivar from China (92.4\%), Evergreen $(92.1 \%)$, Orthega $(91.1 \%)$, and Adam (90.9\%).

Cv. Buyan (30.9\%) and Badyory (42.2\%) had the lowest percentage of germinated seeds.

In literature $[19,20,21]$ there was an association between drought resistance of plants and intensity of development of primary root system in grain crops. In addition, a positive relationship was established between the number of seminal and nodal roots, the mass of the root system, and, as a result, an increase in grain productivity of plants [22].

As a result of the conducted studies, accessions 752A and a local cultivar from China (k-2930) were isolated, which formed a significantly higher (at $\mathrm{P}>0.999$ ) number of seminal roots when germinated in osmotic solution, compared to the control (Fig. 2). Stress conditions did not significantly affect the number of seminal roots in cv. Filippa, a local 
cultivar from China (k-2929), Makbo, Kazminsky, Bear, CDC Mc Gwire, Evergreen, Respect, Medicum 11, Buyan, and Bios-1. All the rest cultivars significantly reduced the number of seminal roots under osmotic stress.

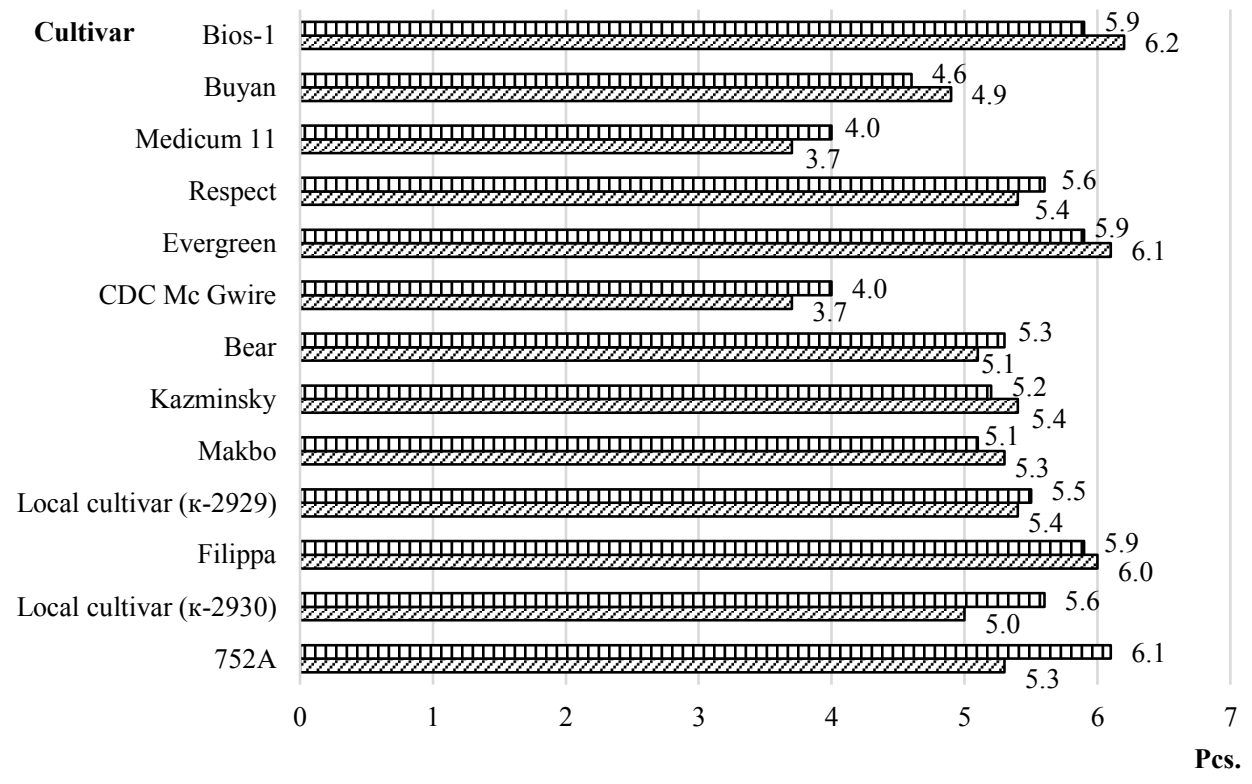

口Test $\mathbf{\square}$ Control

Fig. 2. Number of seminal roots in collection accessions under osmotic stress

In addition to the germination capacity and degree of development of the root system, the RSR index was used to assess the level of cultivar's resistance to the stress factor showing the relative redistribution of plastic flows between the root and above-ground organs which is an important adaptive response of the plant to environmental conditions. Most of the plastic matters are normally transferred to the above-ground organs. In case of resource shortage, as a rule, there is an increase in specific root mass associated with inhibition of shoot growth and simultaneous increase of assimilate inflow to roots which is due to multiple hormonal regulations [23].

The RSR index ranged from a $51.4 \%$ decrease in $\mathrm{cv}$. Mentor to a $459.1 \%$ increase in cv. Filippa. Most of the studied accessions were characterized by high relative RSR, and they differed in the indicator "RSR deviation."

Drought tolerance was characterized by the cv. Bonita, Irbe (PR-3528), Cooper, Danuta, Rodos, Odessky 115, Polarny 14, Adam, Medicum 11, Mie, 121-13, and C-105, combining high laboratory germination capacity in conditions of osmotic stress and relative RSR (tab. 1). In addition, all of these accessions had a slight deviation of RSR. The lowest deviation of RSR among these samples had cv. 121-13 (8.1\%) and Mie (8.3\%), which characterizes them as more drought resistant compared to the rest cultivars. Other cultivars that have high laboratory germination capacity in stressful conditions, but significant deviations in RSR, cannot be classified as drought-resistant.

Table 1. Evaluation of drought resistance of collection accessions having the lowest deviation of RSR

\begin{tabular}{|c|c|c|c|c|}
\hline \multirow{2}{*}{ Cultivar } & \multicolumn{2}{|c|}{ RSR, \% } & \multirow{2}{*}{$\begin{array}{c}\text { Relative } \\
\text { RSR, \% }\end{array}$} & $\begin{array}{c}\text { Deviation in RSR, } \\
\text { \% }\end{array}$ \\
\cline { 2 - 3 } & control & test & \\
\hline Belgorodsky 100 (standard) & 83.3 & 169.2 & 203.0 & 103.0 \\
\hline
\end{tabular}




\begin{tabular}{|l|c|c|c|c|}
\hline Bionic & 123.1 & 99.4 & 80.8 & 19.2 \\
\hline Cooper & 106.3 & 146.4 & 137.7 & 37.7 \\
\hline Danuta & 99.1 & 126.7 & 127.8 & 27.8 \\
\hline 752A & 91.5 & 90.6 & 99.0 & 1.0 \\
\hline Bonita & 91.4 & 118.6 & 129.6 & 29.6 \\
\hline NCL 95098 & 129.0 & 128.8 & 99.8 & 0.2 \\
\hline Local cultivar (к-3506) & 60.5 & 46.1 & 76.3 & 23.7 \\
\hline Odessky 115 & 107.0 & 119.3 & 111.5 & 11.5 \\
\hline Mie & 107.9 & 116.8 & 108.3 & 8.3 \\
\hline Rodos & 77 & 85.7 & 111.4 & 11.4 \\
\hline Polarny 14 & 96.7 & 131.9 & 136.4 & 36.4 \\
\hline Kazminsky & 129.4 & 108.9 & 84.2 & 15.8 \\
\hline Adam & 149.6 & 174.9 & 116.9 & 16.9 \\
\hline Bear & 160.0 & 128.2 & 80.2 & 19.8 \\
\hline Fitzroy & 113.0 & 113.7 & 100.6 & 0.6 \\
\hline Medicum 11 & 97.6 & 130.7 & 134.0 & 34.0 \\
\hline Irbe (PR-3528) & 100.5 & 131.4 & 130.8 & 30.8 \\
\hline C-105 & 96.6 & 79.5 & 82.3 & 17.7 \\
\hline 121-13 & 143.6 & 155.2 & 108.1 & 8.1 \\
\hline
\end{tabular}

Drought-resistant cultivars also include those that did not have a high RSR, but have the lowest deviation of this indicator and high level of laboratory germination capacity: Bionic, 752A, NCL 95098, local cultivar from India (k-3506), Kazminsky, and Bear. A slight deviation of RSR was distinguished by the cv. Fitzroy $(0.6 \%)$, but due to the low germination capacity under stressful conditions they cannot be classified as droughtresistant.

One of the most important tasks of breeding, as before, remains the creation of highyielding barley cultivars. None of the identified drought-resistant accessions, on average for three years of assessment, significantly exceeded the standard cv. Belgorodsky 100 (4.8 $\mathrm{t} / \mathrm{ha}$ ) in terms of productivity. Cv. Bonita, Cooper, Rodos, Kazminsky, etc. were distinguished by high yields at the standard level (LSD $=1.3 \mathrm{t} / \mathrm{ha}, \mathrm{p}=5.73 \%$ ) (Fig. 3).

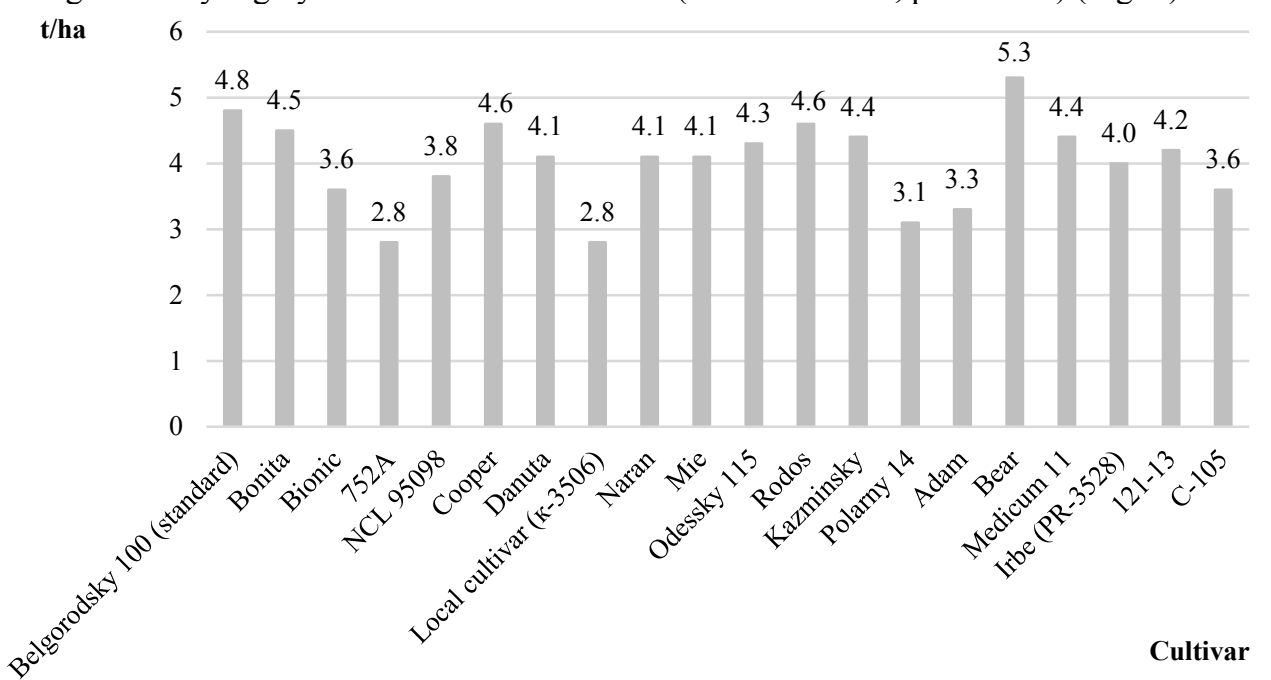

Fig. 3. Yield capacity of barley cultivars resistant to osmotic stress, 2018-2020

The cv. Bear stood out as the most productive one among cultivars resistant to osmotic stress; its yield capacity was $5.3 \mathrm{t} / \mathrm{ha}$ which exceeded this indicator in the standard cultivar by $0.5 \mathrm{t} / \mathrm{ha}$. Cv. $752 \mathrm{~A}(2.8 \mathrm{t} / \mathrm{ha})$, Local cultivar from India (k-3506), Polarny $14(3.1 \mathrm{t} / \mathrm{ha})$, and Adam (3.3 t/ha) showed significantly lower yields compared to the standard cultivar 
The productivity of any crop is an integral indicator that depends on many features and properties of plants. Some of the indicators that determine the potential productivity of the cultivar are elements of the yield structure. It is known that with an increase in the capacity for ear-bearing shoots, the spike length, the number of grains per spike, the 1000-grain mass the yield increases too $[24,25,26]$. As a result of studies, sources for a number of breeding-valuable traits were identified among cultivars resistant to osmotic stress (tab. 2).

Table 2. The main elements of the productivity of cultivars resistant to osmotic stress, 2018-2020

\begin{tabular}{|c|c|c|c|c|c|c|c|c|}
\hline \multirow{3}{*}{ Cultivar } & \multicolumn{2}{|c|}{$\begin{array}{l}\text { Tilling capacity, } \\
\text { stems per plant }\end{array}$} & \multicolumn{4}{|c|}{ Ear parameters } & \multicolumn{2}{|c|}{ Grain mass, $\mathbf{g}$} \\
\hline & \multirow{2}{*}{ total } & \multirow{2}{*}{$\begin{array}{c}\text { Of ear- } \\
\text { bearing } \\
\text { shoots }\end{array}$} & \multirow{2}{*}{$\begin{array}{l}\text { length } \\
\text {, cM }\end{array}$} & \multirow{2}{*}{ density } & \multicolumn{2}{|c|}{ amount, pcs. } & \multirow{2}{*}{$\begin{array}{l}\text { Per } \\
\text { ear }\end{array}$} & \multirow{2}{*}{$\begin{array}{l}\text { Per } \\
\text { plant }\end{array}$} \\
\hline & & & & & spikes & grains & & \\
\hline $\begin{array}{l}\text { Belgorodsky } 100 \\
\text { (standard) }\end{array}$ & 2.4 & 2.1 & 6.2 & 12.8 & 19.2 & 17.6 & 0.90 & 1.51 \\
\hline Bonita & 2.1 & 2.0 & 7.0 & 13.1 & 20.5 & 18.9 & 0.94 & 1.48 \\
\hline Bionic & 2.4 & 2.1 & 6.3 & 13.4 & 20.7 & 18.0 & 0.81 & 1.65 \\
\hline $752 \mathrm{~A}$ & 1.9 & 1.6 & 5.6 & 10.7 & 39.6 & 33.9 & 1.24 & 1.12 \\
\hline NCL 95098 & 3.8 & 3.2 & 6.5 & 12.7 & 19.4 & 17.3 & 0.89 & 1.96 \\
\hline Local cultivar (к-3506) & 2.0 & 1.6 & 6.6 & 10.8 & 49.7 & 36.9 & 0.92 & 1.24 \\
\hline Cooper & 2.6 & 2.3 & 7.2 & 13.0 & 20.8 & 19.5 & 0.96 & 1.69 \\
\hline Danuta & 2.4 & 1.9 & 7.3 & 13.0 & 22.5 & 21.2 & 1.03 & 1.64 \\
\hline Mie & 1.9 & 1.7 & 7.1 & 13.2 & 22.4 & 20.4 & 0.96 & 1.40 \\
\hline Odessky 115 & 2.3 & 2.0 & 6.5 & 12.0 & 19.7 & 17.9 & 0.86 & 1.38 \\
\hline Rodos & 3.0 & 2.5 & 5.8 & 14.6 & 20.4 & 18.8 & 0.95 & 1.91 \\
\hline Kazminsky & 1.4 & 1.3 & 4.1 & 11.7 & 31.0 & 26.3 & 1.06 & 1.22 \\
\hline Polarny 14 & 1.2 & 1.2 & 4.8 & 12.8 & 39.0 & 31.1 & 1.18 & 1.30 \\
\hline Adam & 2.4 & 2.1 & 6.9 & 14.2 & 22.9 & 20.5 & 0.89 & 1.53 \\
\hline Bear & 2.5 & 2.1 & 8.8 & 12.2 & 24.6 & 22.6 & 0.98 & 1.80 \\
\hline Medicum 11 & 2.3 & 1.9 & 7.1 & 12.1 & 18.5 & 16.4 & 0.81 & 1.30 \\
\hline Irbe (PR-3528) & 2.4 & 2.1 & 7.6 & 13.7 & 24.8 & 23.7 & 0.99 & 1.81 \\
\hline C-105 & 2.0 & 1.7 & 5.3 & 12.3 & 43.9 & 36.0 & 1.59 & 2.28 \\
\hline $121-13$ & 1.8 & 1.6 & 7.4 & 11.6 & 20.9 & 19.8 & 0.98 & 1.43 \\
\hline $\mathrm{LSD}_{05}$ & 0.81 & 0.64 & 0.66 & 0.65 & 2.62 & 2.58 & 0.14 & 0.57 \\
\hline
\end{tabular}

The cv. NCL 95098 was characterized by high total tilling capacity and capacity for earbearing shoots; double-row cv. Bonita, Cooper, Danuta, Mie, Rodos, Adam, Bear, Medicum 11, Irbe (PR-3528), and 121-13 as well as multi-row cv. Kazmisnky, Polyarny 14, the Local cultivar from India (to-3506), and C-105 stood out in ear parameters (length, density, number of spikes and grains per ear); in terms of productivity per ear and plants cv. 752A, Kazminsky, Polar 14, and C-105.

\section{Conclusions}

Thus, as a result of the conducted studies sources of breeding-valuable traits were identified for further breeding work to create barley varieties adaptive to the conditions of the Volga- 
Vyatka region. Resistance to an osmotic stress at early stages of an organogenesis is characterized for cv. Bonita, Bionic, Cooper, Danuta, 752A, NCL 95098, a local cultivar from India (to-3506), Odessky 115, Rodos, Kazminsky, Polyarny 14, Adam, Bear, Medicum 11, Irbe (PR-3528), Mie, 121-13, and C-105. The drought-resistant cultivars NCL 95098, Cooper, Bonita, Danuta, Mie, Rodos, Kazminsky, Adam, Bear, Medicum 11, Irbe (PR-3528), 752A, Polarny 14, and C-105, which are distinguished by the elements of yield structure, are suitable for further breeding work taking into account their positive features. It is recommended that the remaining drought-resistant accessions be included in crossing with cultivars having higher productivity.

\section{References}

1. A.F. Tumanian A.F., Wasim Hamdan, N.V. Tyutyuma, RUDN Journal of Agronomy and Animal Industries, 2, 43 (2010)

2. K. Chmielewska, P. Rodziewicz, B. Swarcewicz, A. Sawikowska, P. Krajewski, L. Marczak, D. Ciesiołka, A. Kuczyńska, K. Mikołajczak, P. Ogrodowicz, K. Krystkowiak, M. Surma, T. Adamski, P. Bednarek, M. Stobiecki, Frontiers in plant science, 1108 (2016)

3. V. I. Nikitina, The Bulletin of Omsk SAU, 3(27), 19 (2017)

4. O.V. Levkova, The All-Russia Research and Trade Journal Legumes and groat crops, 4(36), 143 (2020)

5. E. D. Nettevich, Selected Works, 348 (2008)

6. A.S. Kasakova, L.A. Kuleshova, The Bulletin of agricultural science Don, 4 (2018)

7. N.A. Rodina, Breeding of barley in the North-East of Nechernozie, 488 (2006)

8. U.P. Fedulov, V.V. Kotlyarov, K.A. Dotsenko, Plant resistance to adverse environmental factors, 64 (2015)

9. N.H. Samarah, Agronomy Sustainable Development, 25(1), 145 (2005)

10. A.P. Shekhurdin, Selected Works, 32 (1961)

11. N.H. Samarah, V.N.Pakul, S.V.Martynova, D.E.Androsov, International research journal, 2(44), 102 (2016)

12. M.R. Absaludinova, Z.A. Omarova, Modern trends in the development of science and technology, 2(1), 44 (2015).

13. I.N. Nyska, V.P. Petrenkov, Bulletin of the Kursk State Agricultural Academy, 7 (2017)

14. N.N. Anisimova, N.V. Ionova, Grain farming in Russia, 6, 31 (2015)

15. J. Lekesh, I. Baresh, A. Foral, V. Odignal, F. Ruschichka, M. Bobek et al., International comecon list of descriptors for the genus Hordeum L. (subgen. Hordeum), 42 (1983)

16. I.G. Loskutov, O.N. Kovaleva, E.V. Blinova, Methodological Guidelines for the Study and Preservation of the World Collection of Barley and Oats, 64 (2012)

17. G.V. Udovenko, Diagnostics of plant resistance to stress, 277 (1988)

18. B. A. Dospekhov, Methodology of field experiment, 416 (1985)

19. V.N. Pakul, International research journal, 2(44), 102 (2016)

20. P.A. Genkel, Plant Resistance to Drought and Ways to Improve it, 5(1), 237 (1946)

21. V.A. Kumakov, Physiological substantiation of models of wheat varieties, 270 (1985) 
22. V.N. Pakul, Siberian Bulletin of Agricultural Science, 2, 54 (2003)

23. G.R. Kudoyarova, S. Yu. Veselov, I. Yu. Usmanov, Journal of General Biology, 60(6), 633 (1999)

24. D.B. Mergalimov, L.V. Bekenov, V.P. Shamanin, Vestnik NSAU, 1, 28 (2016)

25. S.V. Martynova, V.N. Pakul, D.E. Androsov, Siberian Bulletin of Agricultural Science, 49(5), 11-20 (2019)

26. L.A. Lyapkalo, V.B. Khronyuk, Modern technology and technology, 6 (2016) 